\title{
"To Evaluate the Accuracy of Tanaka Johnston Mixed Dentition Analysis in Gulbarga Population: An In Vitro Study"
}

\author{
Dr. Laique Sami Bangi, Dr. K. K. Reddy, Dr. Abhishek Bansal, Dr.Safiya Sana, \\ Dr.Safeena
}

\begin{abstract}
:
Background:This study was undertaken to evaluate the applicability of Tanaka and Johnston mixed dentition prediction methods on Gulbarga population.

Mesiodistal tooth dimensions of four mandibular incisors, maxillary and mandibular canines and premolar teeth were measured using a digital VernierCalipers calibrated to the nearest of $0.01 \mathrm{~mm}$ from study models representing 50 male and 50 female of Gulbarga subjects. The actual measurements were then compared with the predicted values derived from Tanaka Johnston equation. Correlation and regression analysis were performed between the predicted and actual tooth size for Gulbarga subjects and standard regression equations were developed.

Objectives:To test the reliability of Tanaka Johnston mixed dentition space analysis in Gulbarga population. To determine, if any, sexual dimorphism with respect to Tanaka Johnston mixed dentition analysis.

Materials and Methods: The mesiodistal dimensions of teeth on study casts of 13-16 years (50 males and 50 females were selected) from Gulbarga population were measured. The actual tooth measurements were then compared with predicted values using the Tanaka Johnston equations.
\end{abstract}

Keywords:Digital VernierCallipers,Mesiodistal dimensions of teeth on study casts, Tanaka Johnston mixed dentition analysis.

\section{Introduction}

Early treatment is becoming increasingly popular in modern orthodontic philosophiesand it is imperative that the mixed dentition space analysis is accurately done before such orthodontic treatment is offered[1].During this mixed dentition phase, predicting the size of the un-erupted canines andpremolars relative to the existing arch space available is an important diagnostic process in orthodontics. Early detection of a deficiency in arch length is usually indicative of potential future dental crowding or malalignment.

Mixed dentition analysis involves a decision process whereby the space required for the dentition is subtracted from the space available within the arch. The space required is the sumof the total mesiodistal dimensions of the permanent canines and premolars on each side of the arch plus the width of the four permanent incisors. Un-erupted canine and premolars can be predicted by taking half the width of the mandibular incisors and adding $11.0 \mathrm{~mm}$ for the maxillary teeth and 10.5 for the mandibular teeth. The aforementioned formula can be used for both male and female patients.

The concept of dental space analysis is not a recent idea. Review of the literature indicates attempts to predict the width of the un-erupted permanent canines and premolars were published in the early 1900's and canbe categorized into three basic methods:

- Measurement of the un-erupted teeth on the radiographs[2],[3],[4]

- Use of regression equations that relate the mesiodistal widths of erupted teeth to the mesiodistal widths of unerupted teeth [5],[6]

- A combination of measurements from erupted teeth and radiographs of unerupted teeth.[7],[8],[9]

Typically, the mesiodistal dimensions of unerupted canines and premolars have beenextrapolated from measurements of the erupted permanent mandibular incisors using the Tanaka and Johnston prediction equations ${ }^{5}$.Prediction techniques were developed using a population of "probable"North European ancestry. However neither study qualified the exact origins of thesampled studied. Unlike Moyers, Tanaka and Johnston documented their sample size(506 subjects). In 1975, Bailit[10] discussed the variations in permanent tooth size that exist among different races. Comparisons of the mesio-distal dimensions of maxillary permanent teeth were conducted using a non-described sample of white Americans, Japanese, Australian Aborigines and Norwegian Lapps. From hisdata, Bailit concluded that permanent tooth size does varyamong different races. Specifically, the mesio-distal dimension of the first molar in Australian Aborigines wasalmost 10\% larger than that found in Norwegian Lapps. He also noted that there were racial differences in the relative size of specific teeth. For example, populations of Asian ancestry have large upper lateral incisors compared to their centrals. This trait is 
not demonstrated in the other racial groups listed. Evidence of racial tooth size variability suggests that prediction techniques basedon a single racial sample may not be considered universal.

Therefore, it is of the utmost importance that prediction techniques are interpreted relative to respective racial norms, since failure to consider tooth size racial variations would render the interpretation of Tanakaand Johnston prediction equations[5]as misleading and erroneous.

The purpose of this study is to test the reliability of Tanaka and Johnston equations [5]and determine the sexual dimorphism with respect to Tanaka Johnston mixed dentition analysis. This would be beneficial for Orthodontists in treatment planning in this part of the country.

\section{Aims and Objectives of the study}

1. To test the reliability of Tanaka Johnston mixed dentition space analysis in Gulbarga population.

2. To determine the sexual dimorphism with respect to Tanaka Johnston mixed dentition analysis in Gulbarga population.

\section{Materials And Method}

The sample consists of pre-treatment study models of 100 patients, which include 50 males and 50 females with the age group of 13 to 16 years selected randomly from the records of the patients, reporting to department of orthodontics and Dentofacial Orthopaedics at Al-Badar Rural Dental College and Hospital, Gulbarga, Karnataka. The study models available in the department were duplicated and utilized for the present study.

The criteria for selection of subjects were:

1. Subjects should have ancestors belonging to Gulbarga.

2. All teeth must be present and fully erupted from $2^{\text {nd }}$ molar to $2^{\text {nd }}$ molar

3. Absence of congenital anomalies in the tooth morphology.

4. Intact dentition with no proximal caries or restoration or age related attrition. Subjects with no previous history of orthodontic treatment

5. Subjects with no previous history of Orthodontic treatment.

\section{The measuring device:}

A digital vernier calliper (Aerospace) with least count of $0.01 \mathrm{~mm}$ was used to measure the models. The tips of the calipers were precision engineered to facilitate the greatest degree of accuracy. The mesio-distal dimensions of the teeth were obtained by measuring the maximum distance between approximate surfaces of the teeth.

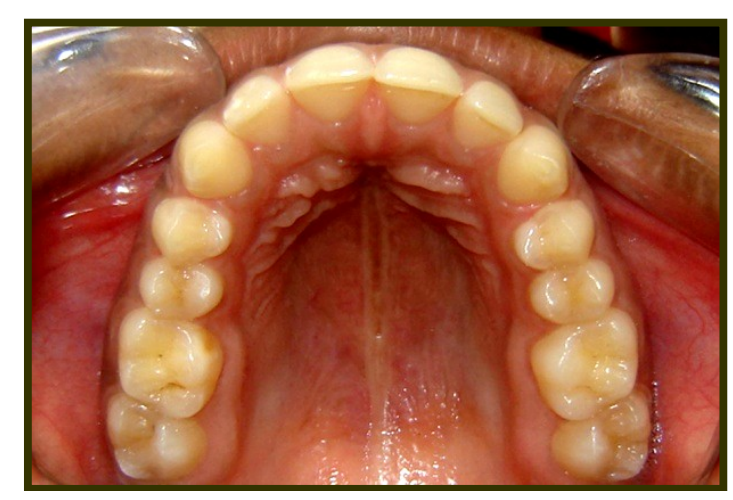



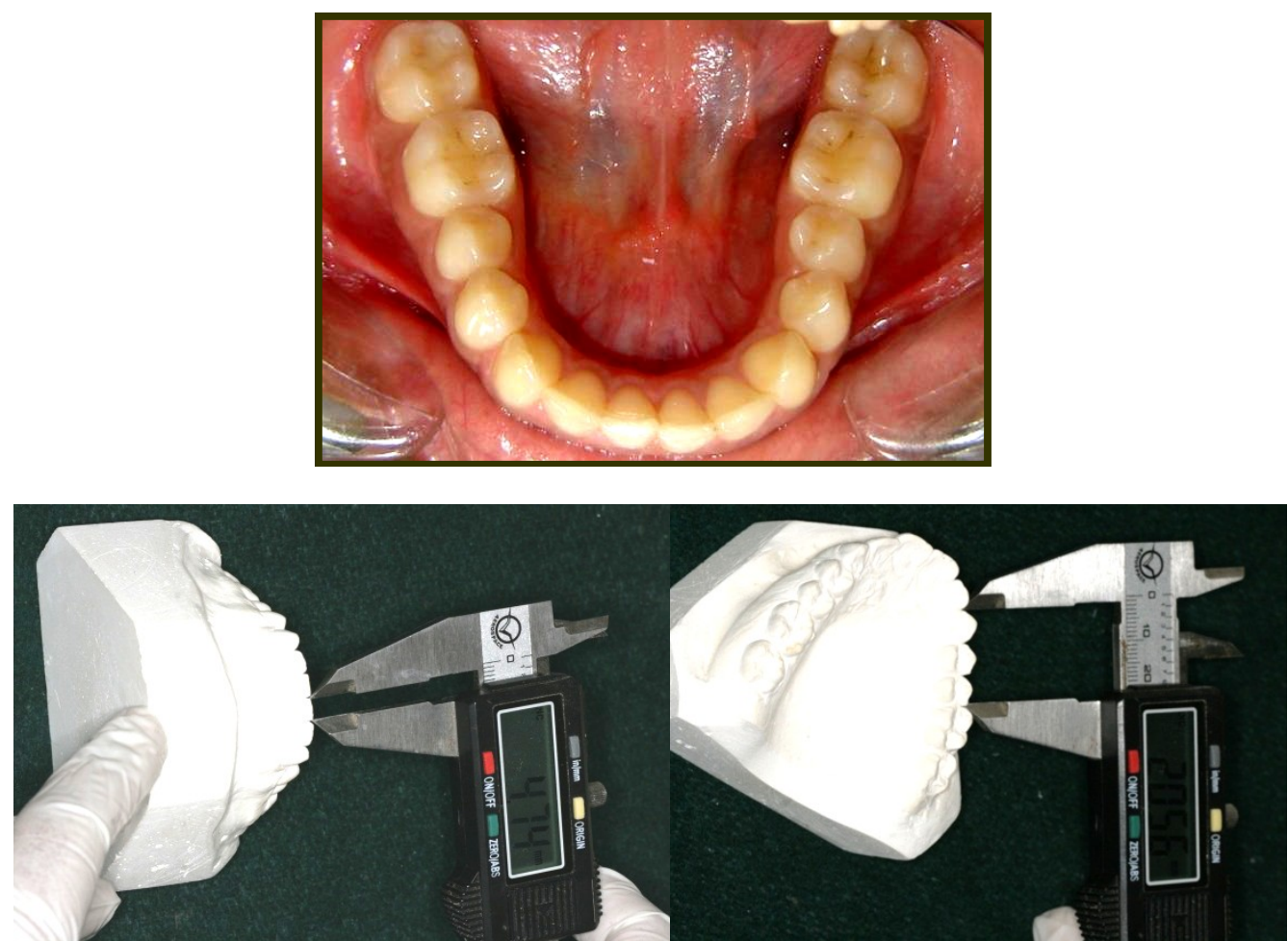

Fig 1- Mesio-distal width of mandibular incisor pre-molars in maxillary arch

Fig 2- Mesio-distal width of canine and

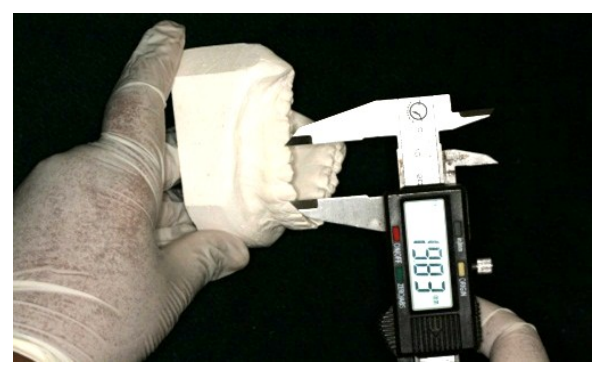

Figure-3: Mesio-distal width of canine and pre-molars in mandibular arch

\section{Teeth measured}

Actual tooth measurements obtained from the sample were compared with the predicted values derived from Tanaka and Johnston equations. In Tanaka and Johnston prediction formula, the sums of the mesio-distal widths of the four mandibular incisors are correlated with the sum of the mesio-distal diameters of the mandibular and maxillary canines and premolars of both arches separately. The Tanaka and Johnston regression equation [5] is as follows:

$\mathrm{Y}=10.5+0.5(\mathrm{X})$ (Mandibular canine-premolar segment)

$\mathrm{Y}=11.0+0.5(\mathrm{X})$ (Maxillary canine-premolar segment)

$\mathrm{Y}=$ the estimate of the sum of the mesio-distal widths of the unerupted canines and premolars on either the right or left side.

$\mathrm{X}=$ the sum of the mesio-distal widths of the four mandibular incisors.

The difference between the predicted widths of the canine and premolars according to Tanaka \& Johnston and the actual widths of the canine and premolars were tested for significance using students paired $t$-test.

\section{Statistical Analysis:}

Descriptive statistics, including the mean, standard deviation, and minimum and maximum values were calculated.

Coefficient of correlation was calculated to find the correlation between canines, premolars and mandibular incisors.

Z-test was calculated to compare tooth dimensions between males and female subjects. 
These data were then used to develop regression equations that could be used clinically for the prediction of total sizes in a Gulbarga sample.

$y=a+b(x)$

$$
\begin{aligned}
& a \text { and } b \text { are regression coefficients } \\
& y=\text { summed width of canines and premolars } \\
& x=\text { summed width of mandibular incisors. }
\end{aligned}
$$

\section{Results}

Data obtained by the study were subjected to statistical analysis. The differences between Gulbarga population \& European ancestry were studied and were analysed for significance.

The Mean value for summed width of mandibular incisors in Gulbarga population for females and males was found to be 21.7 and 21.9 (actual width for maxilla in females and males), 20.6 and 20.4 (actual width for mandible in females and males), 22.5 and 22.4 (predicted width for maxilla in females and males), 21.9 and 21.8 (predicted width of mandible in female and males) (Table 1,Graph-1) with a Standard deviation of 1.05 and 1.41 (actual width for maxilla in females and males), 1.26 and 1.05 (actual width for mandible in females and males), 0.74 and 0.59 (predicted width for maxilla in males and female) 0.57 and 0.75 (predicted width of mandible in female and males) (Table 1).

On comparison of summed of the width of mandibular incisors by $Z$ test in males \& females of Gulbarga population with European descent, results shows statistically significant difference between actual and predicted width 4.68 and 2.22 (for maxilla in females and males) 6.62 and 7.65 (for mandible in females and males), (Table 2).

\section{Z-value to compare the width of maxillary and mandibular for males and females of Gulbarga population} (Table-3)

Actual width for maxillary dentition in females and males is 21.7 and 21.9 (Table-1, graph-2). On comparison of actual width in maxillary dentition for males and females by Z-test is 0.80 (Table-3).

Actual width for mandibular dentition in females and males is 20.6 and 20.4 (Table-1, Graph-2). On comparison of actual width in mandibular dentition for males and females is 0.86 (Table- 3 ).

Predicted width for maxillary dentition in females and males is 22.5 and 22.4 (Table-1, Graph-2). On comparison of predicted width in maxillary dentition for males and females by Z-test is 0.75 (Table-3).

Predicted width for mandibular dentition in females and males is 21.9 and 21.8 (Table-1, Graph-2). On comparison of predicted width in mandibular dentition for males and females by Z-test is 0.75 (Table-3).

Results showed that there is no statistically significant difference of actual and predicted width between males and females (Z-values are less than 1.96 for $\mathrm{p}=0.05)$ (Table-3).

Correlation between sum of the width of mandibular incisors and sum of the width of canines and premolars in males, females by Karl Pearsons correlation coefficient method showed moderately positive correlation (Table-4).

- Correlation coefficient for maxilla is $(\mathrm{r}=0.48, \mathrm{p}<0.05)$,

- Correlation coefficient for mandible is $(\mathrm{r}=0.53, \mathrm{p}<0.05)$

Table-1: Mean \pm SD of actual and predicted width for females and males of Gulbarga population and European Descent (mm)

\begin{tabular}{|l|c|l|l|l|}
\hline \multirow{2}{*}{} & \multicolumn{2}{|c}{ Female } & \multicolumn{2}{c|}{ Male } \\
\cline { 2 - 5 } & Maxillary & Mandibular & Maxillary & Mandibular \\
\hline Actual & $21.7 \pm 1.05$ & $20.6 \pm 1.26$ & $21.9 \pm 1.41$ & $20.4 \pm 1.05$ \\
\hline Predicted & $22.5 \pm 0.59$ & $21.9 \pm 0.57$ & $22.4 \pm 0.74$ & $21.8 \pm 0.75$ \\
\hline
\end{tabular}

Z-value $>1.96$ for $\mathrm{p}=0.05$ (statistically significant difference)

Graph-1: Mean \pm SD of actual and predicted width for females and males of Gulbarga population and European Descent (mm)

Table-2: Z-Value to calculate the actual and predicted width in males and females of Gulbarga Population with European Descent

\begin{tabular}{|c|c|c|c|}
\hline \multicolumn{2}{|c|}{ Female } & \multicolumn{2}{c|}{ Male } \\
\hline Maxillary & Mandibular & Maxillary & Mandibular \\
\hline 4.68 & 6.62 & 2.22 & 7.65 \\
\hline
\end{tabular}

All Z-values $>1.96$ for $p=0.05$ (Significant statistically difference) 
Table-3: $Z$ value to compare the width of maxilla and mandible for males and females

\begin{tabular}{|l|c|c|}
\hline & Maxilla & Mandible \\
\hline Actual & 0.80 & 0.86 \\
\hline Predicted & 0.75 & 0.75 \\
\hline
\end{tabular}

All $\mathrm{Z}$ values are less than 1.96 for $\mathrm{p}=0.05$.

Graph-2: $\mathrm{Z}$ value to compare the width of maxilla and mandible for males and females

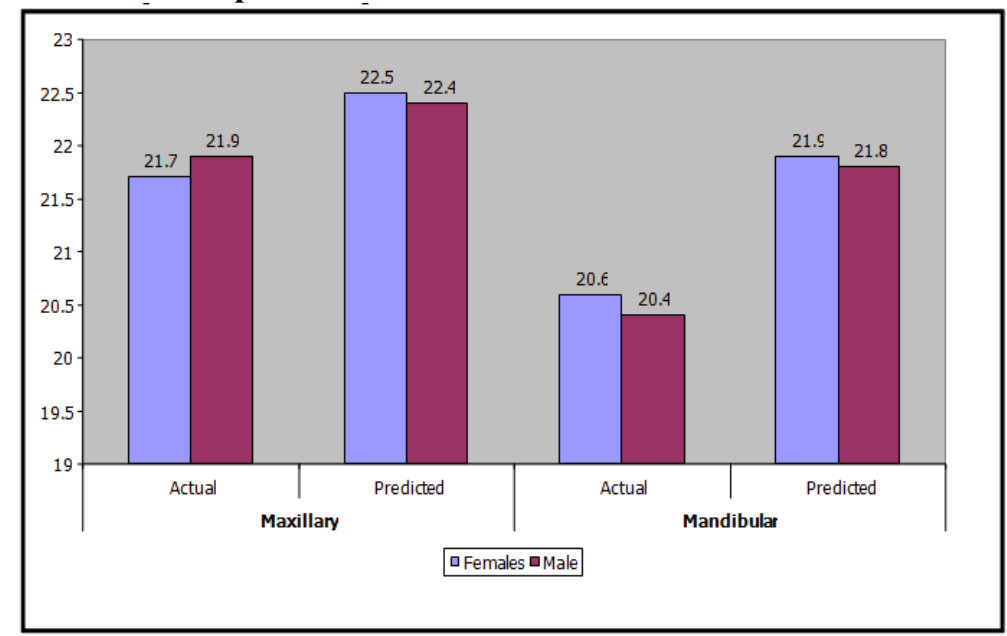

There is no statistically significant difference of actual and predicted width between males and females.

Table-4: Correlation Coefficient to estimate actual width with predicted width for Gulbarga population

\begin{tabular}{|l|c|c|}
\hline & Maxilla & Mandible \\
\hline Correlation Coefficient & 0.48 & 0.53 \\
\hline
\end{tabular}

V. Discussion

An important aspect of diagnosis in the mixed dentition is the determination of the tooth size-arch length relationship. Such a determination is often made prior to eruption of the permanent canines and first and second premolars. The determination of the tooth size-arch length discrepancy in the mixed dentition requires an accurate prediction of the mesio-distal widths of the unerupted permanent teeth.

Each diagnostic analysis utilizing tooth size data is designed to serve at least one of these functions:

1) Prediction of the size of the un-erupted teeth

2) Assessment of tooth size-arch length compatibility with in the same arch.

3) Assessment of tooth size compatibility between two arches.

All of the prediction methods have one unit in common that is, the information about the size of sum of individual erupted teeth. Without information about the size of the individual teeth and groups of teeth, it is difficult for a clinician to make an adequate diagnosis and treatment plan.

Multiple regression analyses have indicated that the sums of the mesio-distal width of the four mandibular permanent incisors are the best predictors for un-erupted canines and premolars. The permanent mandibular incisors were chosen for prediction because they erupt into the oral cavity early in mixed dentition and can be easily measured accurately and are directly in the midst of most space problems.

The maxillary incisors are not used in any of the predictive procedures, since they show too much variability in size, and their correlations with other groups of teeth are of lower predictive value. Therefore, the lower incisors are measured to predict the size of upper as well as lower posterior teeth.

\section{Reliability Of Tanaka Johnston Mixed Dentition Analysis In Gulbarga Population}

The present study attempts to test the reliability of Tanaka Johnston mixed dentition analysis in Gulbarga population.

The observation in the present study showed that for all $\mathrm{Z}$ - values more than 1.96 for $\mathrm{p}=0.05$ (Table 1 $\& 2)$. Hence, there is statistically significant difference between actual and predicted width. These results are in 
concordance to study done by Sharon Lee-Chan et $\mathrm{al}^{25(11)}$, in which they performed mixed dentition analysis for Asian - American population.

There are also several studies done by ShahinEmamiMeibodi et a ${ }^{36(12)}$, performed study on Iranian ethnicity for lower incisor as a predictor for the size of un-erupted canines premolars, SeherGunduzArsalan et $\mathrm{al}^{37(13)}$, conducted mixed dentition analysis in Turkish population, Sri Kuswandari et al ${ }^{38(14)}$ similar study in Indonesian Javanese population, Basil Hussain et $\mathrm{al}^{39(15)}$, conducted similar study on Saudi population and Robert N Staley et al ${ }^{18(16)}$, predicted mesio-distal widths of maxillary permanent canines and premolars in Iowa city. All these studies show statistically significant difference between actual and predicted width which are closely identical to our study.

\section{Sexual Dimorphism}

In the present study all $\mathrm{Z}$ values are less than 1.96 for $\mathrm{p}=0.05$ (Table 3 ). There is no significant difference of actual and predicted width between males and female. Result of this study is in concordance to the study done by Meibodi .S.E et $a^{36(12)}$, which revealed no significant Sexual dimorphism in tooth size. SushmaSonawaneet $\mathrm{al}^{40(17)}$ conducted a study in Maharastra population, who reported the predictive differences between the sexes were statistically not significant in maxilla as well as in mandible.

But the result of our study is dissimilar to the study done by Diagne et $\mathrm{al}^{31(18)}$ in black Senegalese children showed that the mesiodistal width of the mandibular incisors, maxillary and mandibular canine and premolar segments were greater in men than in females and Studies done by D Paula et $\mathrm{al}^{23(19)}$ and Jaroontham and Godfrey ${ }^{41(20)}$ also shows the similar results, and also study done by Ling J.Y.K, Wong R.W.K. ${ }^{42(21)}$, where in the sexual dimorphism was evident between southern Chinese male and female

This study revealed that the equation given by Tanaka-Johnston cannot be applied in the Gulbarga population because high positive correlation was not found.

Considering these differences we have formulated new regression equation for maxilla and mandible in both males and females of Gulbarga population. We feel these would be more appropriate than Tanaka Johnston mixed dentition analysis for this population.

- Maxilla $\mathrm{y}=1.91+0.89 \mathrm{x}$

- Mandible $\mathrm{y}=0.60+0.91 \mathrm{x}$

- $\quad \mathrm{x}$ - Predicted width

- $\quad y$ - Actual width

- We think, it would be constructive and appropriate to undertake further evaluation by involving even larger sample of Gulbarga population.

- Numerous investigators have found differences in mesio-distal tooth sizes and subsequently suggested a number of diagnostic standards in the mixed dentition analysis for various ethnic groups therefore the use of any other equation to estimate mesio-distal width of tooth size may not be accurate for the Gulbarga population in the mixed dentition analysis. The equation in the present study may be useful and serve as a diagnostic guide in the Gulbarga population.

\section{Conclusion}

From the present study following conclusions were made:

1. Data obtained by the study reveals all Z-values more than 1.96 for $p=0.05$. There is statistically significant difference between actual and predicted width.

2. There is no significant difference of actual and predicted width between males and female.

3. The commonly used Tanaka and Johnston methods were not as accurate when applied to our sample of Gulbarga population since it tends to overestimate the actual measurements.

4. The discrepancies noted between the predicted values and those of the present investigation may be the result of racial and ethnic diversity.

5. New regression equations for the Gulbarga population were formulated for predicting the mesio-distal widths of canine and premolars.

The difference found in this present study, as compared to the North East European descent Caucasian population or any other population may be due to racial variation. Variability is a humantrait; therefore it would be premature and erroneous to assume that the newly created prediction analyses canbe universally applied to all Gulbarga people. A larger sample size could lead to the formulation of even more accurate and applicable results for the Gulbarga population.

In the Gulbarga populations there is mixture of basically two different religions. Doing separate study on them may give concluding and much accurate results. 


\section{Bibliography}

[1]. Profitt W R, Fields H W. Contemporary Orthodontics. $3^{\text {rd }}$ edition. St. Louis: Mosby Inc., $2000: 165-70$.

[2]. Nance H N. The limitations of orthodontic treatment I - mixed dentition diagnosis and treatment. Am J Orthod Oral Surg. 1947; 33:4:177-223.

[3]. Bull R L. Radiographic method to estimate the mesiodistal dimension of unerupted teeth. Am J Orthod 1959; 45:711-712

[4]. Huckaba G W. Arch size analysis and tooth size prediction. Dent Clin North Am 1964; 43:431-40.

[5]. Tanaka M M, Johnston L E. The prediction of the size of unerupted canine and premolars in a contemporary orthodontic population. J Am Dent Assoc 1974; 88: 798-801

[6]. Moyers R E. Handbook of orthodontics, $4^{\text {th }}$ edition (1988), Chicago: Yearbook medical publishers, pg 235-240.

[7]. Hixon E H, Oldfather R E. Estimation of the sizes of unerupted canines and premolar teeth. Angle Orthod 1958;28:236-40

[8]. Staley R N, Hoag J F. Prediction of the mesiodistal widths of maxillary permanent canines and premolars. Am. J. Orthod. 1978; 73(2): 169-177.

[9]. Staley R N, Kerber R E. A revision of the Hixon and Oldfather Mixed-Dentition prediction method. Am J Orthod.1980; 78: 296302 .

[10]. Bailit H L. Dental variation among populations. Dent Clin North Am 1975; 19:125-39.

[11]. Lee-Chan S, Jacobson B N, Chwa K H, Jacobson J S. Mixed Dentition for Asian-Americans. Am J OrthodDentofacialOrthop 1998; 113: 293-299.

[12]. ShahinEmamiMeibodi et al. The lower incisors as a predictor for the size of unerupted canine and premolars in the Iranian ethnicity. Orthodontic Waves 2009; 112-115.

[13]. SeherGunduzArsalan et al. Mixed Dentition analysis ia a Turkish population. World J Orthod 2009; 10:135-140.

[14]. Sri Kuswandari et al. Mixed dentition space analysis for Indonesian Javanese children Pediatric Dental Journal 2006 ; 16 (1):74-83.

[15]. Basil Hussain Al-Khadra. Prediction of the size of unerupted canines and premolars in a Saudi Arab population. Am $J$ OrthodDentofacialOrthop 1993; 104: 369-372.

[16]. Staley R N, Shelly T H, Martin J F. Prediction of lower canine and premolar widths in the mixed dentition. Am J OrthodDentofacialOrthop 1979; 76: 300-309.

[17]. SushmaSonawane et al. Comparisons of two non radiographic techniques of mixed dentition analysis and evaluation of their applicability for Marathi population. Scientific Journal Vol II - 2008.

[18]. Diagne, F, Diop-Ba K, Ngom P I, Mbow K. Mixed dentition analysis in a Senegalese population: Elaboration of prediction tables. Am J OrthodDentofacialOrthop 2003; 124: 178-183.

[19]. Paula S D, Almeida M A, Lee P C F. Prediction of mesio-distal diameter of unerupted lower canines and premolars using 45 cephalometric radiography. Am J OrthodDentofacialOrthop 1995; 107: 309-314.

[20]. Jaroontham J, Godfrey K. Mixed dentition space analysis in a Thai population. Euro J Orthod 2000; 22: 127-134.

[21]. John Y K Ling. Tanaka - Johnston Mixed Dentition Analysis for southern Chinese in Hong Kong. Angle Orthod 2006; 76: 632636. 